\title{
Thermal History of the Earth with Consideration of the Formation of Its Core
}

\author{
By \\ Jun IRIYAma \\ Department of Fundamental Science, Faculty of Engineering, \\ Chubu Institute of Technology, Kasugai, Aichi
}

\begin{abstract}
Various possible ways of core formation are tested from the thermal history of the Earth. Calculation shows that the conversion of gravitational to thermal energy from a uniform to. the present differentiated Earth is $1.68 \times 10^{38}$ ergs. It is concluded that the release of the gravitational energy on core formation dominates the thermal state of the Earth.

Earth models in which the core has been growing slowly since $4500 \mathrm{My}$ ago or $3000 \mathrm{My}$ ago fail to meet the requirement of a solid mantle. In these models the present surface heat flows are in excess of the observed heat flow.

Earth models in which the core was substantially complete at $4500 \mathrm{My}$ ago or $3000 \mathrm{My}$ ago within a short period less than $100 \mathrm{My}$ give the observed heat flow.

The gravitational energies released in reconstruction of the terrestrial planets are also calculated. Calculation gives the gravitational energies of $1.02 \times 10^{88} \mathrm{ergs}, 1.10 \times 10^{36} \mathrm{ergs}$, and $1.34 \times 10^{36} \mathrm{ergs}$ for Venus, Mars, and Mercury respectively. The results show that the energies released by the formation of iron cores of the Earth and Venus play an im. portant role for the internal heating of these planets.
\end{abstract}

\section{\$1. Introduction}

It is supposed by many that the Earth's core is composed of molton iron with a possible admixture of some nickel and silicon. The known density of the core is in agreement with this supposition. The mantle is mainly composed of silicates or oxides of light elements. The core is chemically distinct from the mantle. The mass of the core is one-third of the Earth's mass. The separation of the core is thus the principal event of the terrestrial evolution. The reconstruction of the Earth from a uniform, metalsilicate phase mixture to the present state has released substantial amounts of gravitational energy. We should not ignore the gravitational energy when calculating theoretical models of thermal history of the Earth containing the iron core. However, reports of this type of study have apparently not been published to date.

In the present paper the results of some new calculations are discussed. Their main purpose is: a) to compare the thermal history

SMLES Contribution No. 32 . of the Earth assuming a long-enduring and an instantaneous formation of the core resulting from the differentiation of the mantle, and b) to clarify the possible thermal history of the Earth containing the gravitational energy emitted in the process of core formation by comparing theoretical results of the development of temperature within a number of Earth models with observations on the present thermal state of the Earth.

The time-scale of core accumulation is uncertain. Various hypotheses concerning on the period of core growth are classified into two groups as follows: (A) The core has been growing slowly since $3000 \mathrm{My}$ ago (RUNCORN, 1962; 1965). (B) The core was substantially complete at an early stage in the Earth's history within a short period less. than $100 \mathrm{My}$ (STACEY, 1963; BIRCH, 1965; SHIMAZU, 1965; FUJII and UYEDA, 1966). We call $A$ and $B$ processes of the above core separation gradual and rapid formation of the core respectively. These two variants are critically tested with respect to their. thermal history. 
On the basis of a lack of data on the thermal state of the primeval Earth we shall use two models for the initial temperatures of the Earth. In one model the temperature is assumed to be $1200^{\circ} \mathrm{K}$ at the center. We call the model cold model. In the other model the temperature is supposed to be $4000^{\circ} \mathrm{K}$ at the center and to decrease outward along a Simon melting curve. We call the model hot model.

The temperature of the surface is always adopted as equal to $273^{\circ} \mathrm{K}$. The age of the Earth is set equal to $4.5 \times 10^{9}$ years. From this moment is measured the time $t$ used in the calculation.

We shall assume that at that time the metallic iron is preexisted and distributed among silicate phases.

\section{\$2. Analysis and Model of Core Formation}

In this section processes of core formation are analyzed and are classified.

\section{(A) Gradual Formation of the Core (A-1) Initial cold Earth:}

If the Earth originally formed as a gravitational collection of gases or particles at a relatively low temperature, then the initial composition and structure would be expected to be largely uniform throughout. However, an initial loss of gravitational potential energy in the process of planet formation out of particles by accretion is quite large. For instance, for a spherical body with radius $R$ in hydrostatic equilibrium in which density is uniform, the loss of gravitational potential energy (negative), $\Omega$, or the work done by gravitation in drawing together the material from a state of infinite diffusion is determined by

$$
\Omega=-0.3 G M^{2} / R,
$$

where $G=$ gravitational constant and $M=$ total mass (EDDINGTON, 1959, p. 87). The gravitational potential energy becomes $-3 \times 10^{39}$ ergs for the present Earth mass and radius. Let the specific heat be $C_{p}=1.3 \times 10^{7} \mathrm{ergs} / \mathrm{g}-\mathrm{deg}$, the average temperature rise $\Delta T$ becomes

$$
\Delta T=|\Omega| /\left(M C_{p}\right)=4 \times 10^{4} \text { degrees },
$$

which is sufficient to melt the Earth through- out. But, for this consideration, SHImazu (1965) has pointed out that most of the initial loss of gravitational potential energy is quickly radiated back into the space when the accreting material hit at the surface of the condensing planets. Except when dust clouds prevented radiation, this energy would escape almost instantaneously.

From this point of view the initial temperatures within the Earth formed as a result of an accumulation of particles of the gasdust protoplanetary cloud would be low. It seems safe to assume that in the original Earth the temperature at the center would be about $1200^{\circ} \mathrm{K}$ as a result of adiabatic compression (LUBIMOVA, 1958; ANDERSON and PhINNEY, 1967). We shall assume that at that time the gross distribution of the metallic phases and the long-lived isotopes are uniform. The concentration of radioactive elements throughout the Earth until core formation commences is assumed to be equal to that of chondritic meteorities. At the original state of uniform chondritic composition, we put $U=1 \times 10^{-8} \mathrm{~g} / \mathrm{g}, \mathrm{K}^{40}=8 \times 10^{-8} \mathrm{~g} / \mathrm{g}$ (reduced to the present values) and $T h / U=4$. The heavier iron nickel phase begins to migrate toward the center as soon as the Earth becomes warm enough through radioactive decay. If the Earth accreted from chondritic material, the metallic phase would have reached the melting temperature some 1500 My after the completion of the aggregation process for the initial cold Earth (MACDONALD, 1959; IRIYAMA, 1966). It seems safe to assume that in the case the core began to form at a time $1500 \mathrm{My}$, i.e., $3000 \mathrm{My}$ ago. For the first $1500 \mathrm{My}$ there was no core formation. After separation of the core, the abundance of $\mathrm{U}, \mathrm{Th}$, and $\mathrm{K}^{40}$ in the silicate mantle is changed to satisfy the mass conservation, preserving the ratio of $T h / U$.

While the mantle-core separation occurs in the closed system, so that the accompanying release of gravitational energy is largely contained within the Earth. RUNCORN (1965) argues emphatically that the separation of iron toward the center has gradually occurred through the Earth's life. We assume that 


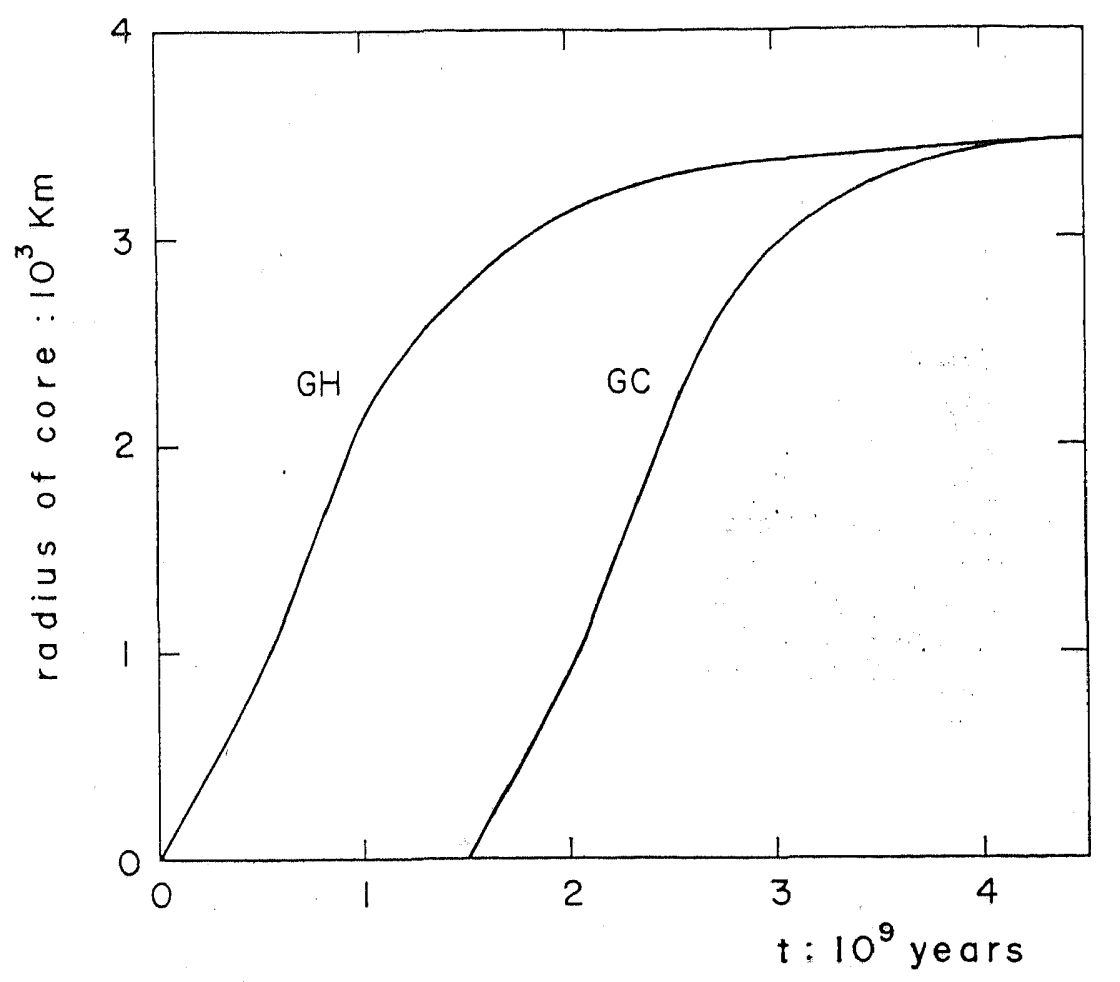

Fig. 1. Diagram of a gradual growth of the Earth's core. GH-Model GH, GC-Model GC [after RUNCORN (1965)].

after RUNCORN the core has started its growth a little over $3000 \mathrm{My}$ ago. The history of growth of the core is given in Figure 1, which is reproduced from that derived by RUNCORN. It is seen that the rate at which iron is added to the core is proportional to the surface area of the core and to the mass of iron remaining in the mantle. The gradual growth of the core provides a source of energy continuously released since $3000 \mathrm{My}$ ago. The initial temperature distribution $T_{0}(r)$ in this case is given in Figure 3 , which is reproduced from tnat calculated by LUBIMOVA. This core formation process is referred to as model GC. $(A-2)$ Initial hot Earth:

If the time between the formation of elements and the aggregation of the Earth was short compared with the half-lives of short-lived isotopes, radiogenic energy due to the isotopes should not be ignored. For instance, MACDONALD (1959) points out that the short-lived isotopes play an important role for the initial heat of the Earth provided we assume that the time between the element formation and the aggregation was $100 \mathrm{My}$. According to his account, the important short-lived nuclides are U-236, Sm-146, Pu-244, and $\mathrm{Cm}-247$. $\mathrm{He}$ argues that if all the heat produced by the four isotopes was retained by the material, then the mean temperature increase of the Earth was about $3000^{\circ} \mathrm{C}$. On the other hand, SHIMAZU (1965) argues that the im. portant short-lived nuclides for heating at the early stage are $\mathrm{Cl}-36$ and $\mathrm{Al}-26$ for the silicate phase and $\mathrm{Fe}-60$ for the metal phase from the quantitative view point.

In either estimate the temperatures within the Earth at $4500 \mathrm{My}$ ago attain to the melting temperature of iron in the mantle. From this point of view it is necessary to assume that the core has started to form at a time 
$4500 \mathrm{My}$ ago. The growth curve of the core is given in Figure 1. The gradual growth of the core provides a source of energy continuously released since $4500 \mathrm{My}$ ago. The initial temperature distribution $T_{0}(r)$ in this case is given in Figure 5. This core formation process is referred to as model GH.

\section{(B) Rapid Formation of the Core}

\section{(B-1) Initial cold Earth:}

The commencement of core differentiation would be determined by melting of the iron and by a reduction in the viscosity of silicate phase in the mantle, as pointed out by TOZER (1965) and UYEDA (1967a). The formation of the core would not proceed until the mantle is, by radioactive heating, to become soft enough to permit the iron to fall. We may take the temperature dependence of the mantle viscosity to be of the form $\exp (E / k T)$ where $E$ is an activation energy and $k$ the Boltzmann's constant. Hence, as Tozer (1965) has argued, the process of core formation releases a lot of energy which will cause a further fall in viscosity, so that this process will quickly establish itself or be catastrophic. The rate of the gravitational energy release will be itself dependent on the rate of core formation in a manner which encourages a catastrophic change.

From this point of view the time-scale of the core accumulation would be a geologically short time less than $100 \mathrm{My}$. Now, if we assume an initially cold Earth, the core is substantially complete at the time between 1500 to $1600 \mathrm{My}$ after the end of the accretion process of the Earth. The rapid growth of the core provides a source of energy fast released at the time between 1500 and 1600 My. The initial temperature distribution $T_{0}(r)$ in this case is given in Figure 7. This core formation process is referred to as model $\mathrm{RC}$.

\section{(B-2) Initial hot Earth:}

From geochronological data, the Earth has an age of about $4500 \mathrm{My}$. SHImazu (1965) has pointed out that this age refers to the time when the upper mantle and the crust can be regarded as a closed system with characteristic $U / P \mathrm{~b}$, and the value of 4500
My is regarded as the age of the upper mantle. The separation of the core affects the $U / P \mathrm{~b}$ ratio of the silicate mantle, for the metal carries down significant amounts of $P \mathrm{~b}$ but not $U$. If the mantle-core separation is continued significantly during the stage of a closed system, the consistent value of 4500 $\mathrm{My}$ for the age of mantle cannot be obtained from rocks differentiated from the mantle at different ages. Hence, SHImazu (1965) argues emphatically that the Earth had separated into the core and the mantle at or before $4500 \mathrm{My}$ ago.

From this point of view it is necessary to assume that the core was substantially complete at the time between 0 to $100 \mathrm{My}$ and that its subsequent growth has been slight. The rapid growth of the core provides a source of energy fast released at the time between 0 to $100 \mathrm{My}$. The initial temperature distribution $T_{0}(r)$ in this case is given in Figure 9. This core formation process is referred to as model RH.

\section{§ 3. Theory}

Here various basic formulas are analyzed as follows:

\section{(1) Loss of gravitational potential energy \\ (1-A) Gradual formation of the core;}

We shall consider a whole series of Earth models, with different radii of the core. We shall assume that the Earth model has the same external radius $R$. We further assume that during the period of core formation the total mass of the Earth is remained constant. To construct a spherically symmetrical Earth model in hydrostatic equilibrium where the rotation is neglected, the following equations are used;

$$
\begin{gathered}
d P=g \rho d r, \\
g=G m / r^{2}, \\
d m=4 \pi r^{2} \rho d r,
\end{gathered}
$$

where $\rho$ is the density at distance $r$ from the center of the Earth, $P$ the pressure, $m$ the mass inside the sphere of radius $r, g$ the gravity field strength, and $G$ the constant of gravitation. 
We know, from the seismological data, the relation of $\rho$ and $P$ for the core. Hence, for the core, we assume an equation of state of the form (BULLEN, 1963, p. 231, model A)

$$
\rho=7.2381+2.0698 P-0.18828 P^{2},
$$

where $P$ is the pressure in units of $10^{12}$ dynes $/ \mathrm{cm}^{2}$.

For the mantle, we assume an equation of state of the form (MACDONALD, 1962)

$$
d \rho / d r=\rho_{0}^{3} g /\left(\alpha \rho^{2}\right),
$$

where $\rho_{0}=$ surface density and $\alpha=$ ratio of incompressibility to density.

$\rho_{0}$ will gradually decrease with time, as the iron separates to form the core. In the uniform Earth $\rho_{0}$ and $\alpha$ are taken to be 4.09 $\mathrm{g} / \mathrm{cm}^{3}$ and $29(\mathrm{~km} / \mathrm{sec})^{2}$ respectively. The boundary conditions at $r=0$ and $R$ are as follows:

$$
\begin{array}{ll}
r=0: & d P / d r=0, \\
& g=0, \\
r=R: & d P / d r=\rho(R) g(R) .
\end{array}
$$

The gravitational potential energy of the Earth, GPE, is expressible in a Protean variety of forms (BIRCH, 1965):

$$
G P E=-4 \pi \int_{0}^{R} g \rho r^{3} d r=-12 \pi \int_{0}^{R} P r^{2} d r .
$$

The release of gravitational potential energy, $G E$, with time or with core radius is given by

$$
G E=\left|G P E_{t_{i}}-G P E_{t_{i-1}}\right|,
$$

where $t$ denotes the time. The rate of heat production, $G$, on core formation is given by

$$
G=G E /(M \cdot \Delta t),
$$

where $M$ is the mass of material subjected to core formation process and $\Delta t$ is a time interval $\left(t_{i}-t_{i-1}\right)$ in the process.

\section{(1-B) Rapid formation of the core;}

For a homogeneous and the present differentiated Earth, we calculate the gravitational potential energies. The loss of gravitational energy is the difference of the two large quantities. As a result of a rapid growth of the core, we shall assume that the energy is rapidly emitted over the whole body of the Earth within a short period less than $100 \mathrm{My}$.

\section{(2) Basic equation of heat transfer}

We shall consider the thermal history of the Earth containing the emission of gravitational energy on core formation. The equation governing the transfer of heat is given by

$$
\partial T / \partial t=\left(1 / \rho C_{p}\right)[\nabla \cdot(K \nabla T)+A+G],
$$

where $K=$ total thermal conductivity,

$A=$ rate of heat production by radioactivity,

$G=$ rate of heat production by gravitation,

$C_{p}=$ specific heat $=1.26$ joules $/ g$-deg.

We shall take the thermal conductivity in the mantle to be of the form

$$
K=K_{\text {photon }}+K_{\text {phonon }} \text {. }
$$

The photon conductivity $\left(K_{\text {photon }}\right)$ is given by

$$
K_{\text {photon }}=16 n^{2} \beta T^{3} / 3 \varepsilon,
$$

where $n^{2}=$ refractive index $=3, \varepsilon=$ opacity $=10$ $\mathrm{cm}^{-1}$, and $\beta$ stands for the Stefan-Boltzmann constant. For the opacity value as $\varepsilon=10 \mathrm{~cm}^{-1}$, present calculations would remain valid also if the exciton conductivity is of importance in the lower mantle.

The phonon conductivity $\left(K_{\text {phonon }}\right)$ is given by

$$
K_{\text {phonon }}=B / T,
$$

where the constant $B$ is determined from the condition that on the earth's surface (where $T=277^{\circ} \mathrm{K}$ ) the thermal conductivity $K_{\text {phonon }}$ should be equal to the conductivity of the crustal rocks $K=0.0334$ joules $/ \mathrm{cm}$-sec-deg.

The thermal conductivity of the core is assumed to be due to free electron or 0.418 joules/cm-sec-deg.

\section{§4. Results}

(A) Gradual formation of the core

(A-1) Initial cold Earth GC;

In model $\mathrm{GC}$ we investigate the thermal history of an initially cold Earth with consideration of the energy emitted in a gradual growth of the core. The densities for the 
Table 1. Density and pressure in the undifferentiated Earth.

\begin{tabular}{r|c|c}
\hline $\begin{array}{c}\text { Radius } \\
\mathrm{km}\end{array}$ & $\begin{array}{c}\text { Density } \\
\mathrm{g} / \mathrm{cm}^{3}\end{array}$ & $\begin{array}{c}\text { Pressure } \\
\mathrm{Mb}\end{array}$ \\
\hline 0 & 6.96 & 2.150 \\
300 & 6.95 & 2.139 \\
600 & 6.93 & 2.112 \\
900 & 6.90 & 2.074 \\
1200 & 6.87 & 2.024 \\
1500 & 6.82 & 1.962 \\
1800 & 6.77 & 1.890 \\
2100 & 6.70 & 1.808 \\
2400 & 6.63 & 1.715 \\
2700 & 6.54 & 1.613 \\
3000 & 6.45 & 1.503 \\
3300 & 6.34 & 1.385 \\
3600 & 6.22 & 1.260 \\
3900 & 6.09 & 1.129 \\
4200 & 5.94 & 0.993 \\
4500 & 5.77 & 0.854 \\
4800 & 5.58 & 0.712 \\
5100 & 5.38 & 0.569 \\
5400 & 5.14 & 0.428 \\
5700 & 4.87 & 0.289 \\
6000 & 4.56 & 0.155 \\
6300 & 4.19 & 0.029 \\
6371 & 4.09 & 0.000 \\
\hline
\end{tabular}

initial, undifferentiated Earth are listed in Table 1.

For the present Earth (BULlaRd, 1964, p. 96 , Table 4), the gravitational potential energy is $-2.488 \times 10^{39} \mathrm{ergs}$; for the undifferentiated Earth, $-2.290 \times 10^{39}$ ergs. The total loss of the gravitational energy due to the coremantle separation becomes $1.98 \times 10^{88}$ ergs. However, the lost gravitational energy is not completely converted to heat. After UREY (1952, p. 176) and BIRCH (1965) we assume that some $15 \%$ of the loss of gravitational energy remains as strain energy in the Earth's interior. Therefore, the net energy change in reconstruction of the Earth is $1.68 \times 10^{38}$ ergs. This is 1.5 times greater than the total amounts of heat $1.10 \times 10^{38}$ ergs liberated by radioactivity in the chondritic Earth. It is assumed that the gravitational energy has been gradually emitted over the whole body

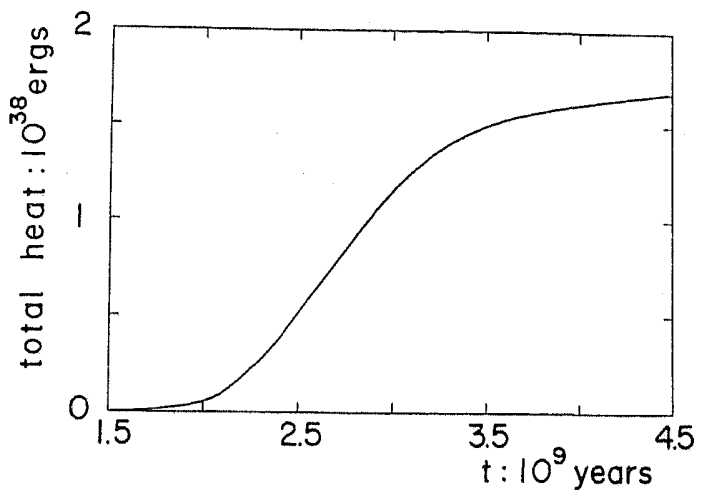

Fig. 2. Total thermal energy released by a gradual growth of the core up to various times for model GC.

of the Earth since $3000 \mathrm{My}$ ago. The total thermal energy released by the gradual growth of the core up to various times is shown in Figure 2. For the values in the model, the mean rate of the gravitational energy release is $9.37 \mathrm{ergs} / \mathrm{g}$-year.

In the present calculations we shall use three models about the concentration of radioactive elements in the mantle. In one model, as a result of the gradual growth of the core since $3000 \mathrm{My}$ ago, we assume that the radioactivity has been gradually concentrated in the upper $600 \mathrm{~km}$ of the Earth since $3000 \mathrm{My}$ ago. In a second model we assume that the radioactivity has been gradually concentrated in the upper $200 \mathrm{~km}$ since $3000 \mathrm{My}$ ago. Finally, for the sake of comparison, it is assumed that the radioactivity has been gradually concentrated in the whole mantle since $3000 \mathrm{My}$ ago. These three models are referred to as model GC-U6, GC-U2, and GC-M respectively.

The development of temperature as a function of time within model GC-U6 is shown in Figure 3. At the stage of uniform Earth the temperature increased slowly with time. After the beginning of the core-mantle separation it began to increase rapidly, and at $t=$ $3.5 \times 10^{9}$ years this rapid increase ceased. At $t>3.5 \times 10^{9}$ years the temperature in the interior increases slowly with time until the present time, while in the first few hundred kilometers below the surface it decreases 


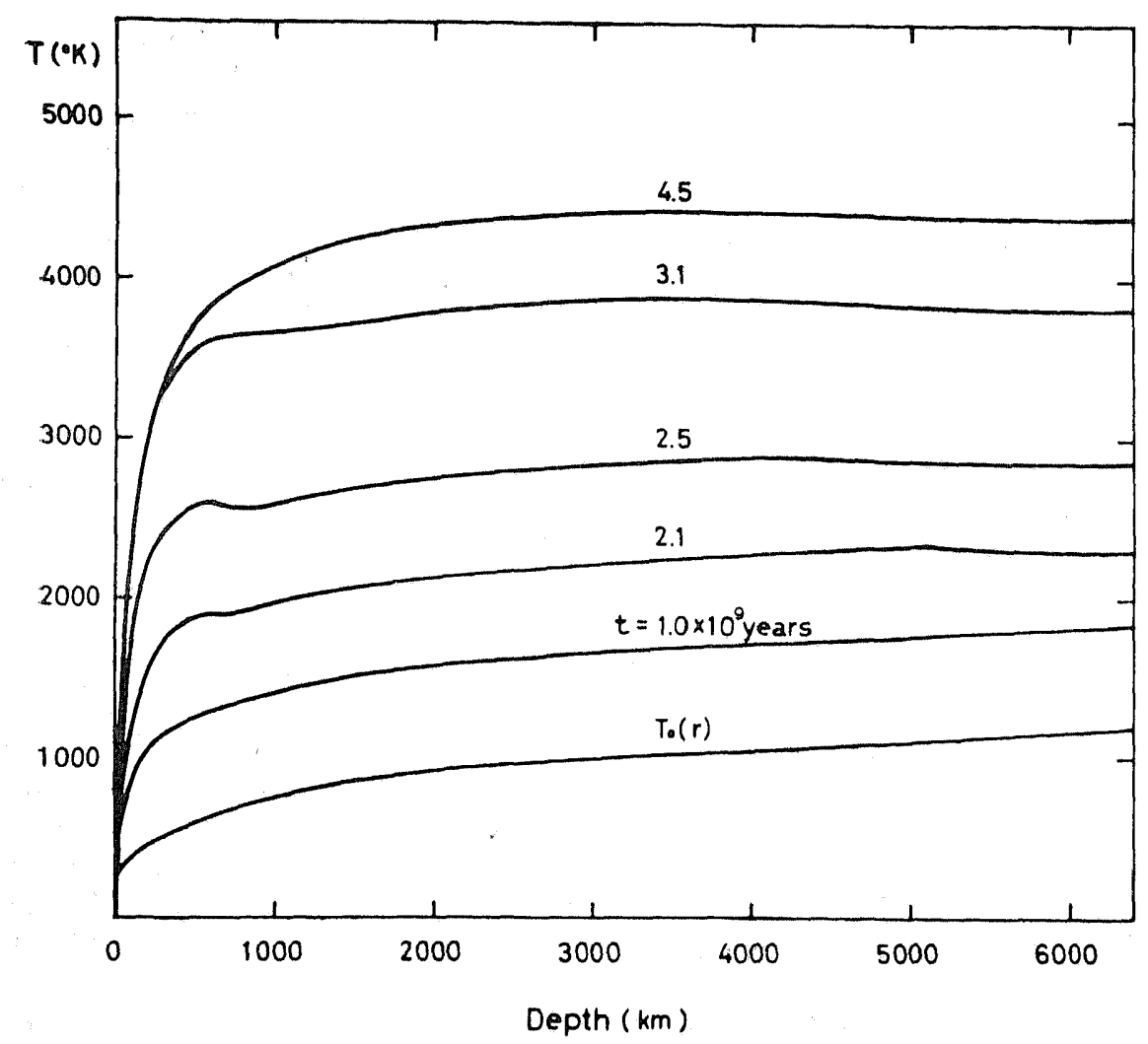

Fig. 3. The development of the temperature distribution within model GC-U6.

Table 2. Melting temperatures of diopside (MACDONALD, 1959).

\begin{tabular}{c|r|r|r|r|r}
\hline Depth $(\mathrm{km})$ & 300 & 600 & 1000 & 1500 & 2000 \\
\hline Melting point $\left({ }^{\circ} \mathrm{K}\right)$ & 2520 & 2990 & 3870 & 4570 & 5190 \\
\hline
\end{tabular}

slowly with time until the present time. The present temperature is $4390^{\circ} \mathrm{K}$ at the Earth's center, $4410^{\circ} \mathrm{K}$ at the core-mantle boundary, which exceeds the melting temperature of diopside at depths between 100 and $1500 \mathrm{~km}$ (see Table 2). The low temperature state within the core is due to a lack of radioactive heat sources within the metallic core. At the time between 1.6 to $3.0 \times 10^{9}$ years the build-up of radioactive heat sources near the surface raised the temperature of the material at the $600 \mathrm{~km}$ depth above the temperature at a greater depth within the mantle.

In models GC-U6, GC-U2, and GC-M the present temperature distributions are listed
Table 3. Present temperature distributions for GC models.

\begin{tabular}{c|c|c|c}
\hline $\begin{array}{c}\text { Depth } \\
\text { km }\end{array}$ & $\begin{array}{c}\text { Model } \\
\text { GC-U6 } \\
\mathrm{T},{ }^{\circ} \mathrm{K}\end{array}$ & $\begin{array}{c}\text { Model } \\
\text { GC-U2 } \\
\mathrm{T},{ }^{\circ} \mathrm{K}\end{array}$ & $\begin{array}{c}\text { Model } \\
\text { GC-M } \\
\mathrm{T},{ }^{\circ} \mathrm{K}\end{array}$ \\
\hline 100 & 2340 & 2390 & 2080 \\
200 & 3000 & 2470 & 2710 \\
400 & 3600 & 3380 & 3320 \\
600 & 3870 & 3650 & 3670 \\
800 & 4010 & 3850 & 3910 \\
1000 & 4120 & 3990 & 4080 \\
1500 & 4280 & 4220 & 4350 \\
2000 & 4370 & 4340 & 4480 \\
2900 & 4410 & 4410 & 4510 \\
4000 & 4420 & 4420 & 4430 \\
5000 & 4400 & 4400 & 4380 \\
6370 & 4390 & 4390 & 4350 \\
\hline
\end{tabular}

in Table 3. The present temperature within model GC-M is, at all depths, about 1000-1400 


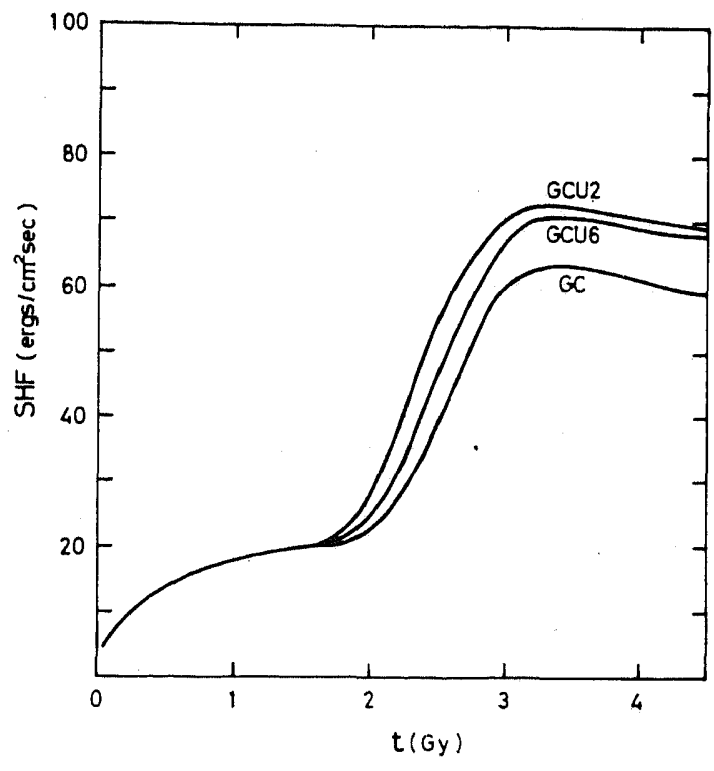

Fig. 4. Variation of surface heat flow with time for $\mathrm{GC}$ models.

degrees higher than that calculated by MACDONALD (1959, his model 14) disregarding the energy released by the formation of the core.

Figure 4 shows the history of surface heat flow for GC models. The almost constant surface heat flow was reached at the end of the uniform Earth and after the beginning of the core-mantle separation it began to increase rapidly. At $t>3.3 \times 10^{9}$ years the heat flow decreases gradually with time until the present time. In all these models the maximum value of the heat flow took place at $t=3.3 \times 10^{9}$ years, i.e., $1.2 \times 10^{9}$ years ago, which occurred some $1.8 \times 10^{9}$ years after the beginning of the core-mantle separation. For model GC-U6, the final surface heat flow is $69.2 \mathrm{ergs} / \mathrm{cm}^{2}-\mathrm{sec}$; for model GC-U2, $70.9 \mathrm{ergs}$ $/ \mathrm{cm}^{2}$-sec; for model GC-M, $60.5 \mathrm{ergs} / \mathrm{cm}^{2}-\mathrm{sec}$. In models GC-U6 and GC-UC the present heat flows are in excess of the observed heat flow (UYEDA, 1967b), and the present temperatures exceed the melting temperature of diopside at depths between 100 and $1500 \mathrm{~km}$. This is the result of the gradual emission of gravitational energy.

\section{(A-2) Initial hot Earth (GH);}

In model $\mathrm{GH}$ we investigate the thermal history of an initially hot Earth with consideration of the energy emitted in a gradual growth of the core. It is assumed that the. gravitational energy has been gradually emitted over the whole body of the Earth since $4500 \mathrm{My}$ ago. For the values in the model, the mean rate of the gravitational energy release is $6.25 \mathrm{ergs} / \mathrm{g}$-year.

In the present calculations we shall use. three models about the concentration of radioactive elements in the mantle. In one model, as a result of the gradual growth of the core. since $4500 \mathrm{My}$ ago, we assume that the radioactivity has been gradually concentrated in. the upper $600 \mathrm{~km}$ of the Earth since $4500 \mathrm{My}$ ago. In a second model we assume that the radioactivity has been gradually concentrated in the upper $200 \mathrm{~km}$ since $4500 \mathrm{My}$ ago. Finally, we assume that the radioactivity has been gradually concentrated in the whole mantle since $4500 \mathrm{My}$ ago. These three models are referred to as model GH-U6, $\mathrm{GH}-\mathrm{U} 2$, and GH-M respectively.

The development of temperature as a function of time within model GH-U6 is shown in Figure 5. It is seen that, after a rapid increase in temperature, at $t>2.2 \times 10^{\circ}$ years. the temperature at depths between 100 and $5500 \mathrm{~km}$ decreases with time until the present time, while near the Earth's center there is a continual increase in temperature. At $t=2.2 \times 10^{9}$ years the temperature in the mantle attained to the maximum. The buildup of radioactive heat sources near the surface is assumed in this model. However, the temperature of the material at the $600 \mathrm{~km}$ depth has not been raised above the temperature at a greater depth within the mantle. This is the result of the high initial temperature. The present temperature is $6460^{\circ} \mathrm{K}$ at the Earth's center, $5900^{\circ} \mathrm{K}$ at the core-mantle boundary, which exceeds the melting temperature of diopside at depths between 100 and $2900 \mathrm{~km}$.

In models $\mathrm{GH}-\mathrm{U} 6, \mathrm{GH}-\mathrm{U} 2$, and $\mathrm{GH}-\mathrm{M}$ the present temperature distributions are listed in Table 4. These present temperatures lie 


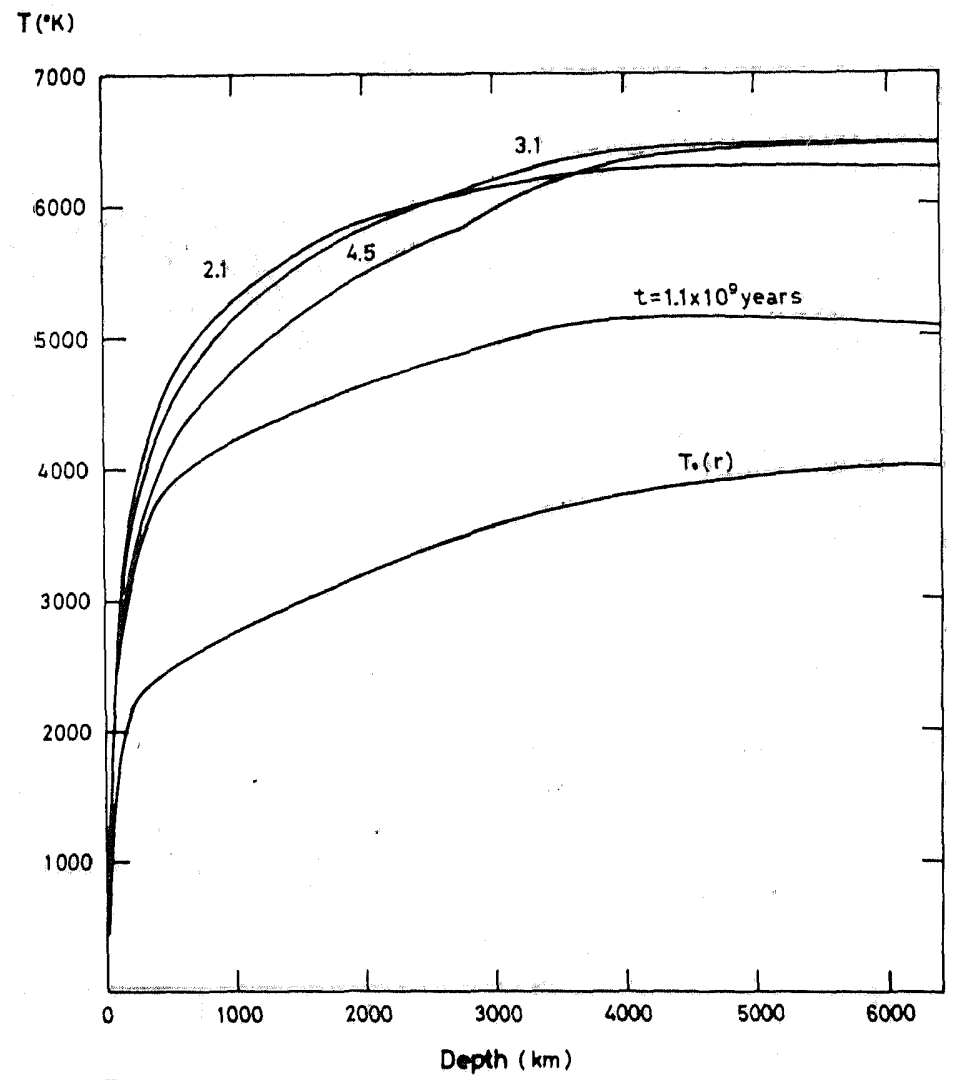

Fig. 5. The development of the temperature distribution within model GH-U6.

Table 4. Present temperature distributions for $\mathrm{GH}$ models.

\begin{tabular}{c|c|c|c}
\hline $\begin{array}{c}\text { Depth } \\
\text { km }\end{array}$ & $\begin{array}{c}\text { Model } \\
\text { GH-U6 } \\
\text { T, }{ }^{\circ} \mathrm{K}\end{array}$ & $\begin{array}{c}\text { Model } \\
\text { GH-U2 } \\
\text { T, }{ }^{\circ} \mathrm{K}\end{array}$ & $\begin{array}{c}\text { Model } \\
\text { GH-M } \\
\mathrm{T},{ }^{\circ} \mathrm{K}\end{array}$ \\
\hline 100 & 2540 & 2500 & 2380 \\
200 & 3250 & 3210 & 3070 \\
400 & 3960 & 3760 & 3800 \\
600 & 4340 & 4140 & 4250 \\
800 & 4590 & 4430 & 4580 \\
1000 & 4790 & 4670 & 4840 \\
1500 & 5200 & 5120 & 5320 \\
2000 & 5490 & 5440 & 5640 \\
2900 & 5900 & 5870 & 6040 \\
4000 & 6320 & 6320 & 6410 \\
5000 & 6430 & 6430 & 6480 \\
6370 & 6460 & 6460 & 6490 \\
\hline
\end{tabular}

well above the estimated melting temperature of diopside in the mantle. Thus, GH models fail to meet the requirement of a solid mantle. This results from the gradual emisssion of gravitational energy and high initial tem. perature. In model $\mathrm{GH}-\mathrm{U} 2$ the present temperature is higher than that of GH-U6 in the uppermost layer of the Earth. In model GH-M the present temperatures is higher than that of model GH-U6 at all depths greater than $900 \mathrm{~km}$.

Figure 6 shows the history of surface heat flow for $\mathrm{GH}$ models. At the very beginning stage in the Earth's history the heat flow decreased slightly with time. This is due to the high initial temperature. At the time between 0.3 to $1.8 \times 10^{9}$ years the heat flow increased rapidly with time, but at $t>1.8$ $\times 10^{\circ}$ years it decreases with time until the present time. In GH models there was a maximum surface heat flow at $t=1.8 \times 10^{9}$ years or $2.7 \times 10^{\circ}$ years ago. The maximum heat flow occurred $1.8 \times 10^{\circ}$ years after the 
beginning of the core-mantle separation. For model GH-U6, the present surface heat flow is $76.0 \mathrm{ergs} / \mathrm{cm}^{2}-\mathrm{sec}$; for model GH-U2, 76.6 ergs $/ \mathrm{cm}^{2}$-sec; for model GH-M, $70.5 \mathrm{ergs} / \mathrm{cm}^{2}$ sec. In all these models the present flows are in excess of the observed heat flow.

(B) Rapid formation of the core

$(B-1)$ Initial cold Earth $(R C)$;

In model $\mathrm{RC}$ we investigate the thermal history of an initially cold Earth with consideration of the energy emitted in a rapid growth of the core. It is assumed that the energy had been rapidly emitted over the whole body of the Earth at the time between 1.5 to $1.6 \times 10^{9}$ years.

In the present calculations we shall use three models about the concentration of radioactive elements in the mantle. In one model, as a result of the rapid growth of the core at $t=1.5 \times 10^{9}$ years, we assume that the radioactivity had been rapidly concentrated in the upper $600 \mathrm{~km}$ of the Earth at the time be-

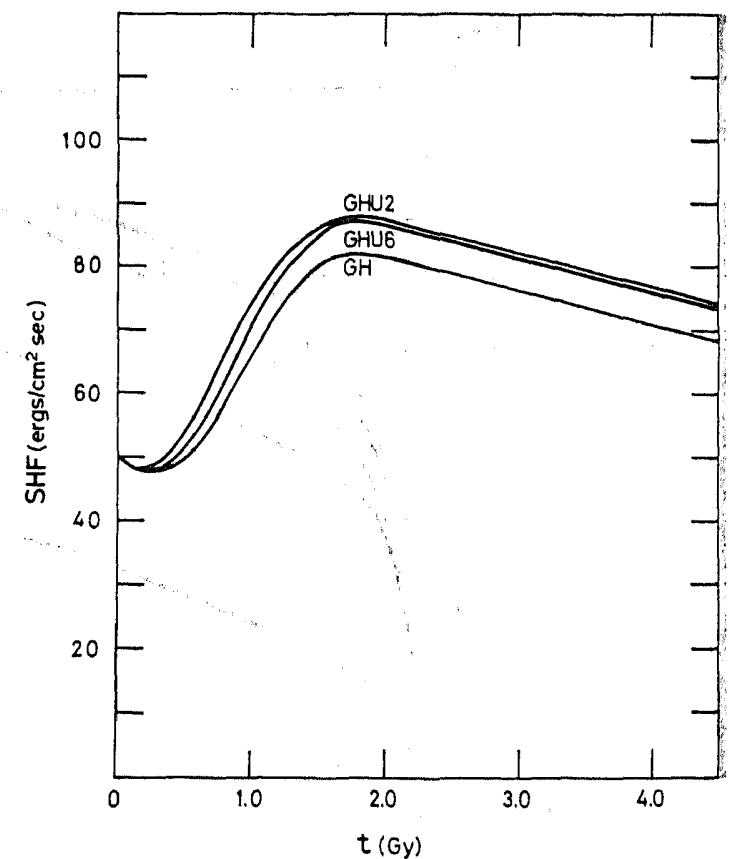

Fig. 6. Variation of surface heat flow with time. for $\mathrm{GH}$ models.

\section{$T\left({ }^{\circ} \mathrm{K}\right)$}

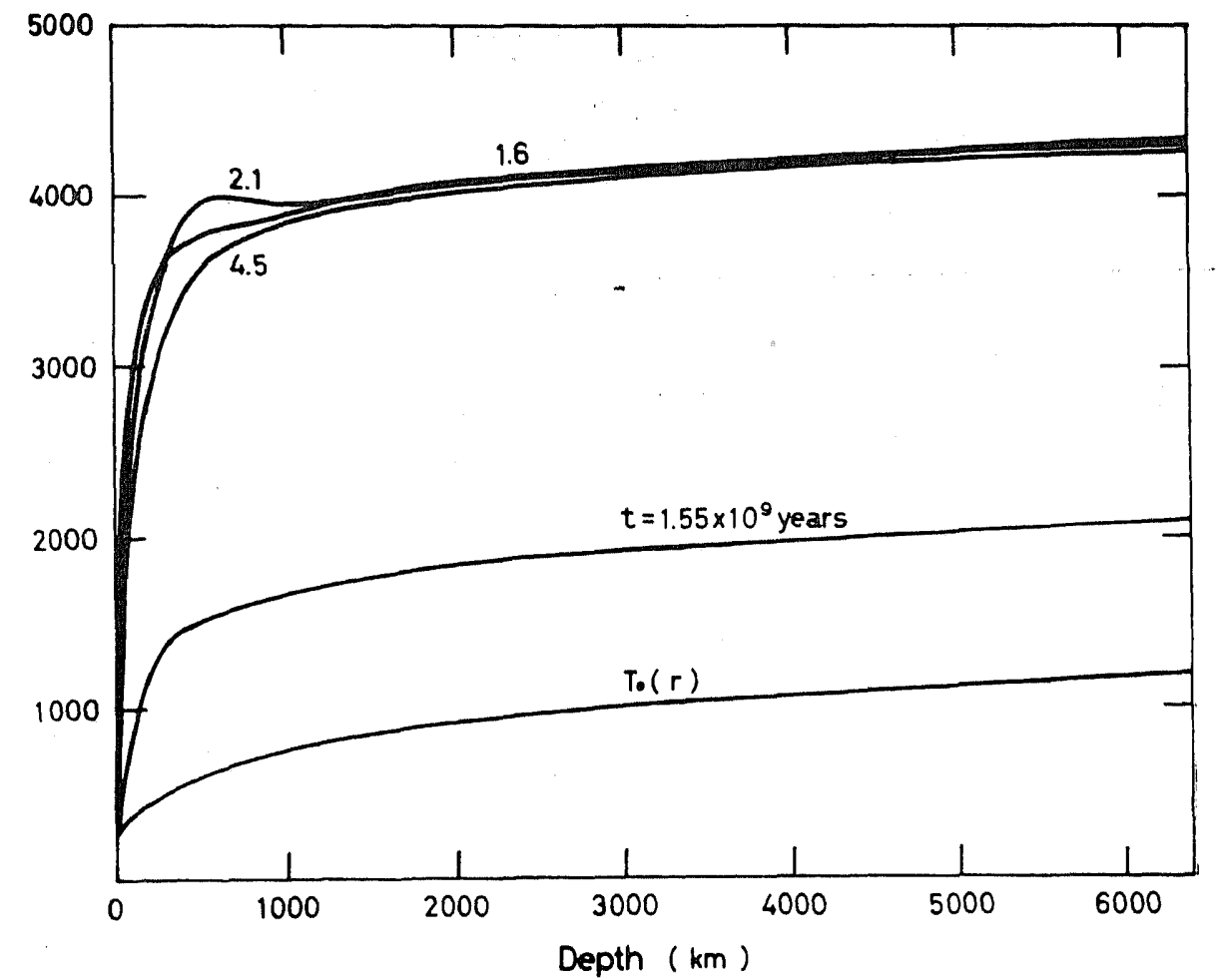

Fig. 7. The development of the temperature distribution within model RC-U6. 
tween 1.5 to $1.6 \times 10^{9}$ years. In a second model we assume that the radioactivity had been rapidly concentrated in the upper $200 \mathrm{~km}$ at the time between 1.5 to $1.6 \times 10^{\circ}$ years. Finally, for the sake of comparison, it is assumed that the radioactivity had been rapidly concentrated in the whole mantle at the time between 1.5 to $1.6 \times 19^{9}$ years. These three models are referred to as model RC-U6, RC-U2, and RC-M respectively.

The development of temperature as a function of time within model RC-U6 is shown in Figure 7. It is seen that at all depths there was a sharp increase in temperature at the time between 1.55 to $1.65 \times 10^{9}$ years. After the very rapid rise in temperature, the outer layers of the Earth cool rapidly, while at all depths greater than $1400 \mathrm{~km}$ temperature does not greatly change with time. It is clearly seen that the gravitational energy has dominated the thermal history of the Earth. The present temperature is $4260^{\circ} \mathrm{K}$ at the Earth's center, $4100^{\circ} \mathrm{K}$ at the coremantle boundary, which exceeds the melting temperature of diopside at depths between 100 and $900 \mathrm{~km}$.

In models RC-U6, RC-U2, and RC-M the present temperature distributions are listed in Table 5. In model RC-U2 the present temperature is higher than that of RC-U6 in the

Table 5. Present temperature distributions for RC models.

\begin{tabular}{c|c|c|c}
\hline $\begin{array}{c}\text { Depth } \\
\text { km }\end{array}$ & $\begin{array}{c}\text { Model } \\
\text { RC-U6 } \\
\text { T, }{ }^{\circ} \mathrm{K}\end{array}$ & $\begin{array}{c}\text { Model } \\
\text { RC-U2 } \\
\text { T, K }\end{array}$ & $\begin{array}{c}\text { Model } \\
\text { RC-M } \\
\text { T, }{ }^{\circ} \mathrm{K}\end{array}$ \\
\hline 100 & 2150 & 2160 & 1810 \\
200 & 2820 & 2720 & 2440 \\
400 & 3390 & 3030 & 3050 \\
600 & 3640 & 3260 & 3410 \\
800 & 3740 & 3420 & 3660 \\
1000 & 3810 & 3540 & 3850 \\
1500 & 3930 & 3760 & 4150 \\
2000 & 4000 & 3910 & 4320 \\
2900 & 4100 & 4070 & 4370 \\
4000 & 4180 & 4180 & 4250 \\
5000 & 4230 & 4230 & 4240 \\
6370 & 4260 & 4260 & 4260 \\
\hline
\end{tabular}

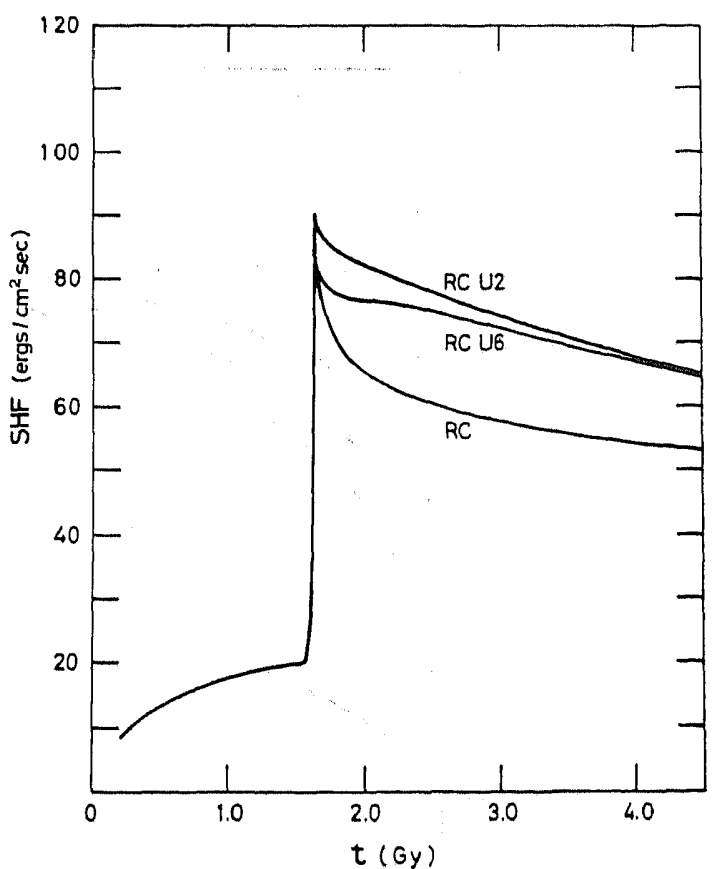

Fig. 8. Variation of surface heat flow with time for RC models.

uppermost layer, which exceeds the melting temperature of diopside at depths between 100 and $700 \mathrm{~km}$.

Figure 8 shows the history of surface heat flow for RC models. In all these models, at $t=1.6 \times 10^{9}$ years, there was a sharp increase in heat flow followed by a rapid decrease. The maximum value of the heat flow took place at $t=1.63 \times 10^{9}$ years, i.e., $2.87 \times 10^{\circ}$ years ago, which occurred about $1.3 \times 10^{8}$ years after the differentiation of the core. For model $\mathrm{RC}-\mathrm{U} 6$, the present surface heat flow is 62.8 ergs $/ \mathrm{cm}^{2}$-sec; for model RC-U2, $63.1 \mathrm{ergs} / \mathrm{cm}^{2}$ $\mathrm{sec}$; for model RC-M, $51.4 \mathrm{ergs} / \mathrm{cm}^{2}-\mathrm{sec}$, which are in agreement with the observed heat flow. In model RC-U2 the present heat flow is almost identical with that in model RC-U6. This results from the rapid core-mantle separation and the rapid near surface concentration of the radioactive heat sources at a time $3.0 \times 10^{9}$ years. Hence, in future, the heat flow in model RCU2 will be lower than that in model RC-U6. $(B-2)$ Initial hot Earth (RH):

In model $\mathrm{RH}$ we investigate the thermal history of an initially hot Earth with con- 
$T(\cdot K)$

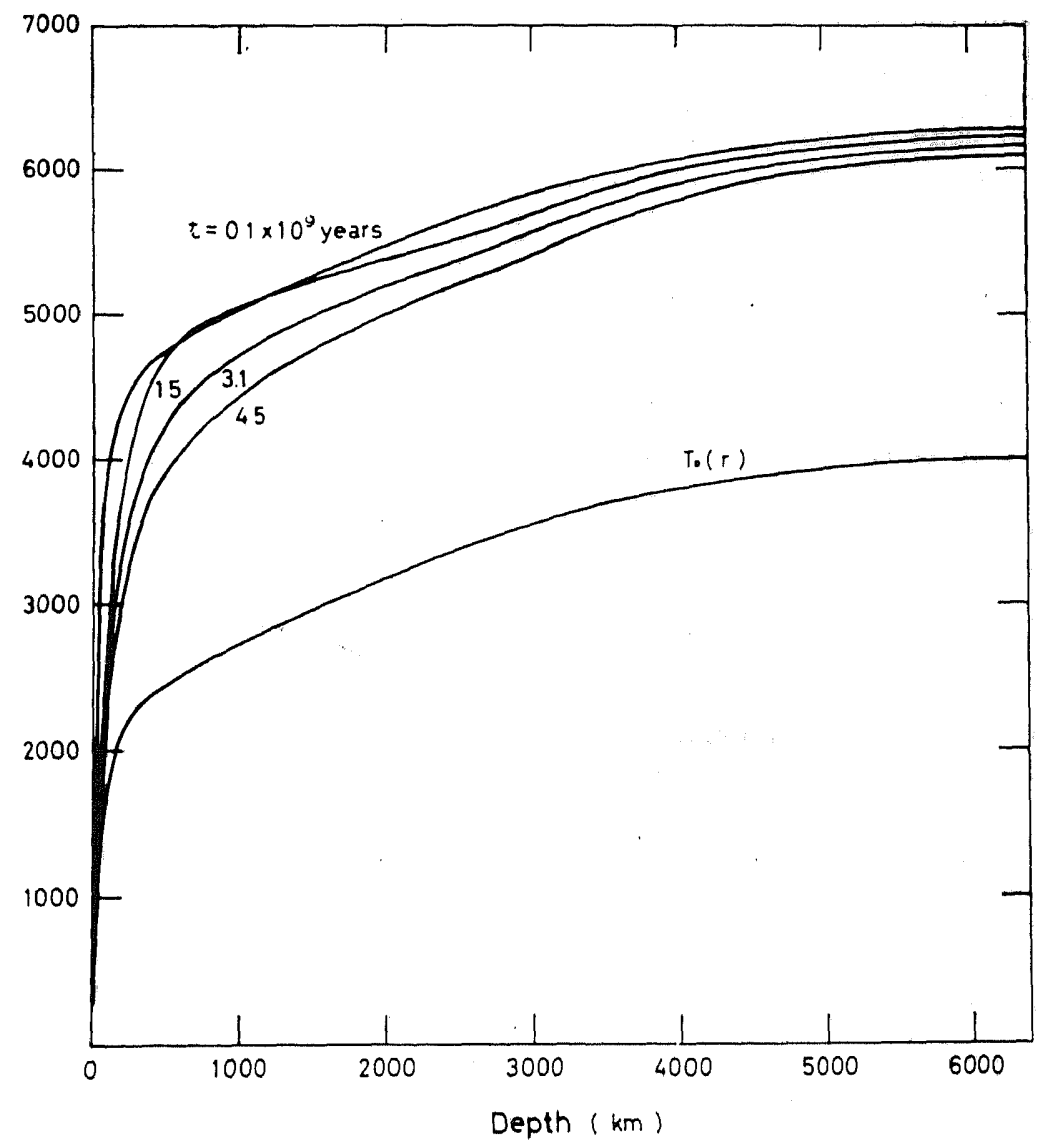

Fig. 9. The development of the temperature distribution within model RH-U6.

sideration of the energy emitted in a rapid growth of the core. It is assumed that the energy had been rapidly emitted over the whole body of the Earth at the time between 0.0 to $1.0 \times 10^{8}$ years.

In the present calculations we shall use three models about the concentration of radioactive elements in the mantle. In one model, as a result of the rapid growth of the core at $t=0.0$, we assume that the radioactivity had been rapidly concentrated in the upper $600 \mathrm{~km}$ of the Earth at the time between 0.0 to $1.0 \times 10^{8}$ years. In a second model we assume that the radioactivity had been rapidly concentrated in the upper $200 \mathrm{~km}$ at the time between 0.0 to $1.0 \times 10^{8}$ years. Finally, we assume that the radioactivity had been rapidly concentrated in the whole mantle at the time between 0.0 to $1.0 \times 10^{8}$ years. These three models are referred to as model RH-U6, RH-U2, and RH-M respectively.

The development of temperature as a function of time within model RH-U6 is shown in Figure 9. It is seen that at all depths there was a sharp increase in temperature at the time between 0.2 to $1.1 \times 10^{8}$ years. This brief temperature rise at the very beginning soon ceased and cooling commenced. At $t>1.1 \times 10^{8}$ years the outer layers of the Earth cool rapidly, while at all depths greater than $3000 \mathrm{~km}$ the temperature decreases slowly with time until the present time. It is clearly seen that the gravitational energy has dominated the thermal history of the Earth. The rate of cooling was greater in the past than it is now. This is due to the rapid formation 
Table 6. Present temperature distribution for $\mathrm{RH}$ models.

\begin{tabular}{c|c|c|c}
\hline $\begin{array}{c}\text { Depth } \\
\text { km }\end{array}$ & $\begin{array}{c}\text { Model } \\
\text { RH-U6 } \\
\text { T, }{ }^{\circ} \mathrm{K}\end{array}$ & $\begin{array}{c}\text { Model } \\
\text { RH-U2 } \\
\text { T, }{ }^{\circ} \mathrm{K}\end{array}$ & $\begin{array}{c}\text { Model } \\
\text { RH-M } \\
\text { T, }{ }^{\circ} \mathrm{K}\end{array}$ \\
\hline 100 & 2330 & 2290 & 2140 \\
200 & 3160 & 2920 & 2860 \\
400 & 3710 & 3370 & 3560 \\
600 & 4050 & 3690 & 4000 \\
800 & 4250 & 3930 & 4310 \\
1000 & 4420 & 4130 & 4550 \\
1500 & 4740 & 4510 & 5000 \\
2000 & 4980 & 4810 & 5320 \\
2900 & 5370 & 5250 & 5670 \\
4000 & 5800 & 5760 & 5960 \\
5000 & 6000 & 5990 & 6060 \\
6370 & 6100 & 6100 & 6120 \\
\hline
\end{tabular}

of the core and the upper mantle, and the high initial temperature. The present temperature is $6100^{\circ} \mathrm{K}$ at the Earth's center, $5370^{\circ} \mathrm{K}$ at the core-mantle boundary, which exceeds the melting temperature of diopside at depths between 100 and $1700 \mathrm{~km}$.

In models RH-U6, RH-U2, and RH-M the present temperature distributions are listed in Table 6. In model RH-U2 the present temperature is lower than that in model RH-U6 at all depths, which exceeds the melting temperature of diopside at depths between 100 and $1200 \mathrm{~km}$. In model RH-M the present temperature is higher than that in model RH-U6 at all depths greater than $700 \mathrm{~km}$. This results from the uniform distribution of radioactive heat sources in the mantle.

Figure 10 shows the history of the surface heat flow for RH models. In all these models, at the very beginning, there was a sharp increase in surface heat flow followed by a rapid decrease. The maximum value of the heat flow took place at $t=1.1 \times 10^{8}$ years, i.e., $4.39 \times 10^{\circ}$ years ago, which occurred some $1.1 \times 10^{8}$ years after the differentiation of the core. For model RH.U6, the present surface heat flow is $68.7 \mathrm{ergs} / \mathrm{cm}^{2}$-sec; for model RH$\mathrm{U} 2,67.4 \mathrm{ergs} / \mathrm{cm}^{2}$-sec; for model RH-M, 62.4 ergs $/ \mathrm{cm}^{2}$-sec. In model RH-U2 the modern value is in rough agreement with the observ-

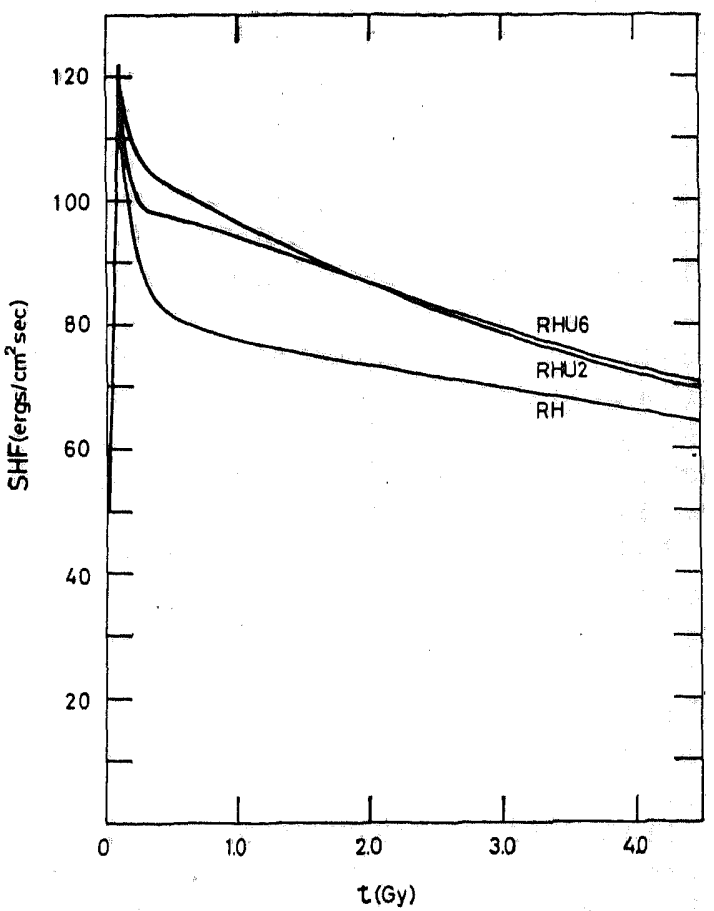

Fig. 10. Variation of surface heat flow with time for $\mathrm{RH}$ models.

ed heat flow. The heat flow in model RH-U2 has been lower than that in model RH-U6 since $2400 \mathrm{My}$ ago. This results from the rapid core-mantle separation and the rapid near surface concentration of the radioactive heat sources at a time $4.5 \times 10^{\circ}$ years ago.

\section{§5. Discussion and Conclusions}

In the process of the core formation, gravitational energy is transformed to thermal energy, to the amount of about 2800 joules/g on an average value for the whole mass of the Earth. This is equivalent to an average rise of temperature of about $2200^{\circ}$. The energy is higher than that given by RUNCORN (1965) and BIRCH (1965) using different methods and is lower than that given by UREY (1952), STACEY (1963), and SHIMAZU (1963) using approximate methods. The energy due to the formation of the core during geological time makes it difficult to account for an appropriate heat flow and a solid mantle. The large amount of energy released favors the view that the core was substantially complete 
at the time between $4500 \mathrm{My}$ and $3000 \mathrm{My}$ ago, and that its process reached completion in a geologically short time. A rapid growth of the core is also confirmed by STACEY (1963), Tozer (1965), and Shimazu $(1965,1967)$ by different thermodynamical calculations. For the moon, IRIYAMA and SHIMAZU (1967) have obtained a similar conclusion by a simplified calculation. For the Earth's mantle, a different view has been obtained by LEE (1968). He argues that the mantle has differentiated slowly throughout the Earth's history by selective fusion of the silicates. This will be the subject for a future study.

The main factor to control the internal temperature is gravitational energy due to the core-mantle seperation. The molten state of the core is possible to attain even if the Earth is formed by accretion of cold materials and the core is lacking in radioactive heat sources.

The author has calculated total radiogenic energy $(R E)$, total heat loss $(L E)$, gravitational energy $(G E)$, and strain energy $(S E)$ :

$$
\begin{aligned}
& R E=\int_{0}^{\tau} d t \int_{M} \sum_{i} H_{i} \exp \left(-\lambda_{i} t\right) d M, \\
& L E=4 \pi R^{2} \int_{0}^{\tau} l(t) d t,
\end{aligned}
$$

where $\tau$ is the age of the Earth, $\lambda_{i}$ is the decay constant of the element $i, H_{i}$ is its rate of heat generation, and $l(t)$ is the surface heat flow value at time $t$. We assume that the radioactivity of the Earth equals that of chondritic meteorites (see Section 2-A-1). After integrating we obtain:

$$
R E=1.10 \times 10^{38} \mathrm{ergs} .
$$

For the surface heat flow value $l(t)$ we adopt that of model RC-U2 in Section 4-B-1. After integrating we obtain:

$$
L E=0.387 \times 10^{38} \mathrm{ergs} .
$$

As described in Section 4-A-1, the value GE$\mathrm{SE}$ is $1.68 \times 10^{38} \mathrm{ergs}$, which gives the total release of thermal energy on core formation process. The value $\mathrm{RE}+\mathrm{GE}-\mathrm{LE}-\mathrm{SE}=2.39$ $\times 10^{38}$ ergs gives the total heat accumulated during the Earth's evolution (model RC-U2).

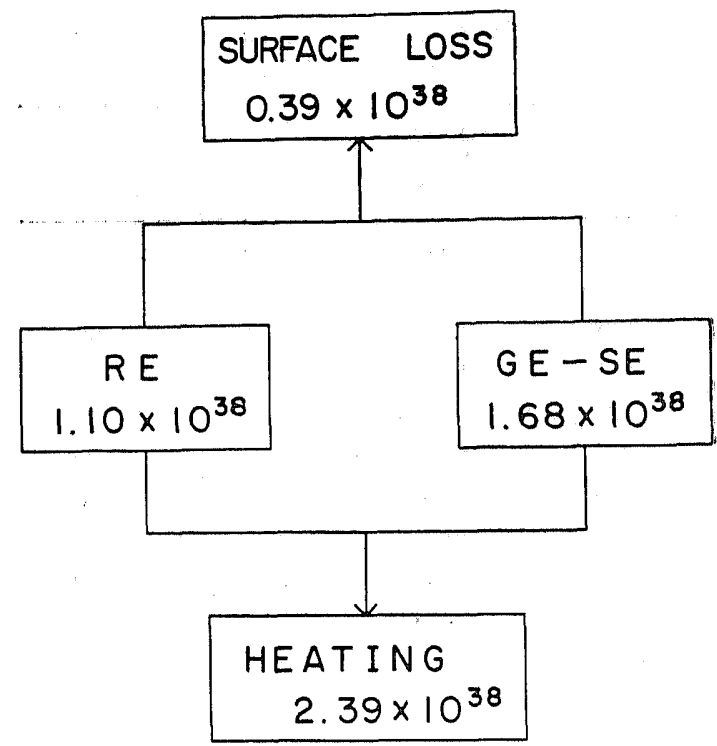

Fig. 11. The diagram of energy balance during the Earth's evolution (model RC-U2).

The total heat loss LE is lower than that suggested by SHIMAZU (1963) and, however, is within the range given by LUBIMOVA (1969). The scheme of energy balance during the Earth's evolution is shown in Figure 11.

Calculations given in Section 3-1 yield values of energies released during the core formation process of Venus, Mars, and Mercury. Data which enter into the calculations are summarized in Tables 7, 8, 9, and 10. Table 7 shows parameters for density

Table 7. Parameters for density models of Venus, Mars, and Mercury.

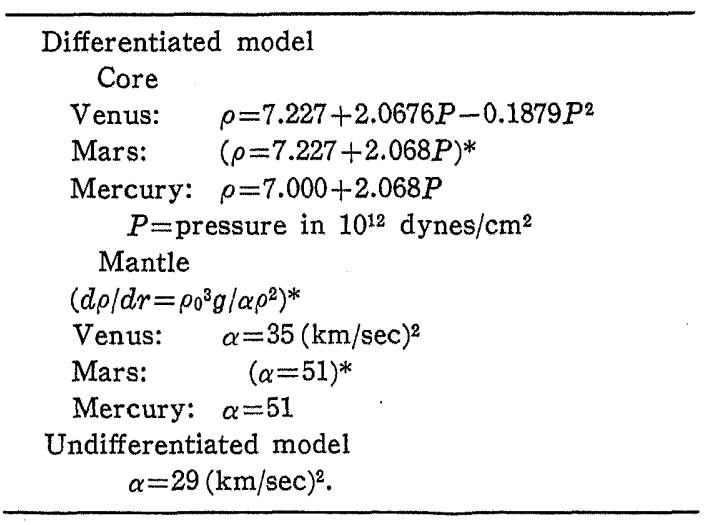

* MacDonald (1962). 
Table 8. Density and pressure distributions for the differentiated and the undifferentiated models of Venus.

\begin{tabular}{|c|c|c|c|c|}
\hline \multirow{2}{*}{$\underset{\mathrm{km}}{\text { Radius }}$} & \multicolumn{2}{|c|}{ Undifferentiated } & \multicolumn{2}{|c|}{ Differentiated } \\
\hline & $\begin{array}{l}\text { Density } \\
\mathrm{g} / \mathrm{cm}^{3}\end{array}$ & $\begin{array}{c}\text { Pressure } \\
\mathrm{Mb}\end{array}$ & $\begin{array}{c}\text { Density } \\
\mathrm{g} / \mathrm{cm}^{3}\end{array}$ & $\begin{array}{c}\text { Pressure } \\
\mathrm{Mb}\end{array}$ \\
\hline 0 & 6.50 & 1.725 & 11.69 & 2.951 \\
\hline 300 & 6.49 & 1.715 & 11.66 & 2.919 \\
\hline 600 & 6.47 & 1.692 & 11.59 & 2.845 \\
\hline 900 & 6.44 & 1.658 & 11.48 & 2.738 \\
\hline 1200 & 6.41 & 1.615 & 11.33 & 2.600 \\
\hline 1500 & $6: 36$ & 1.561 & 11.15 & 2.434 \\
\hline 1800 & 6.31 & 1.499 & 10.92 & 2.242 \\
\hline 2100 & 6.25 & 1.427 & 10.65 & 2.028 \\
\hline 2400 & 6.17 & 1.347 & 10.33 & 1.794 \\
\hline 2700 & 6.09 & 1.258 & 9.97 & 1.545 \\
\hline 3000 & 5.99 & 1.163 & 9.57 & 1.286 \\
\hline 3150 & & & 9.36 & 1.153 \\
\hline 3150 & & & $\begin{array}{c}\text { Boundary } \\
5.16\end{array}$ & $\begin{array}{l}\text { of core } \\
1.153\end{array}$ \\
\hline 3300 & 5.88 & 1.061 & 5.11 & 1.082 \\
\hline 3600 & 5.76 & 0.953 & 5.02 & 0.945 \\
\hline 3900 & 5.63 & 0.840 & 4.93 & 0.813 \\
\hline 4200 & 5.48 & 0.724 & 4.83 & 0.685 \\
\hline 4500 & 5.31 & 0.605 & 4.73 & 0.560 \\
\hline 4800 & 5.12 & 0.484 & 4.63 & 0.436 \\
\hline 5100 & 4.91 & 0.364 & 4.52 & 0.314 \\
\hline 5400 & 4.67 & 0.245 & $\begin{array}{c}4.40 \\
\text { Boundary }\end{array}$ & 0.195 \\
\hline 5400 & & & 3.57 & 0.195 \\
\hline 5700 & 4.39 & 0.130 & 3.38 & 0.102 \\
\hline 6056 & 3.99 & 0.000 & 3.11 & 0.000 \\
\hline
\end{tabular}

models of these planets. Tables 8,9 , and 10 show the calculated densities and pressures for the undifferentiated and the differentiated models of Venus, Mars, and Mercury respectively. The gravitational potential energies for the undifferentiated Venus, Mars, and Mercury are, respectively, $-1.594 \times 10^{89} \mathrm{ergs}$, $-4.855 \times 10^{87} \mathrm{ergs}$, and $-1.777 \times 10^{37} \mathrm{ergs}$. The gravitational energies for the differentiated Venus, Mars, and Mercury are, respectively, $-1.696 \times 10^{39}$ ergs, $-4.965 \times 10^{37}$ ergs, and $-1.911 \times 10^{37}$ ergs. The values of energy change in reconstruction of these planets are presented in Table 11 for comparison with
Table 9. Density and pressure distributions for the differentiated and the undifferentiated models of Mars.

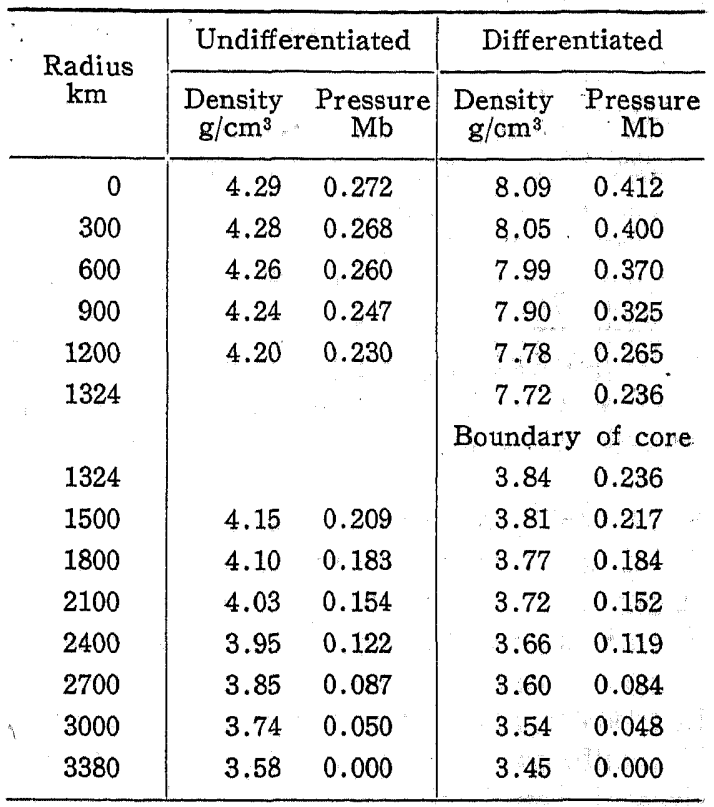

Table 10. Density and pressure distributions for the differentiated and the undifferentiated models of Mercury.

\begin{tabular}{r|rc|rc}
\hline \multirow{2}{*}{$\begin{array}{c}\text { Radius } \\
\mathrm{km}\end{array}$} & \multicolumn{2}{|c|}{ Undifferentiated } & \multicolumn{2}{|c}{ Differentiated } \\
\cline { 2 - 5 } & $\begin{array}{c}\text { Density } \\
\mathrm{g} / \mathrm{cm}^{3}\end{array}$ & $\begin{array}{c}\text { Pressure } \\
\mathrm{Mb}\end{array}$ & $\begin{array}{c}\text { Density } \\
\mathrm{g} / \mathrm{cm}^{3}\end{array}$ & $\begin{array}{c}\text { Pressure } \\
\mathrm{Mb}\end{array}$ \\
\hline 0 & 5.70 & 0.263 & 7.80 & 0.386 \\
300 & 5.69 & 0.259 & 7.77 & 0.374 \\
600 & 5.65 & 0.242 & 7.72 & 0.347 \\
900 & 5.60 & 0.219 & 7.63 & 0.304 \\
1200 & 5.52 & 0.189 & 7.51 & 0.249 \\
1500 & 5.43 & 0.152 & 7.37 & 0.180 \\
1800 & 5.31 & 0.109 & 7.21 & 0.101 \\
1943 & & & 7.12 & 0.059 \\
& & & Boundary & of core \\
1943 & & & 3.14 & 0.059 \\
2100 & 5.17 & 0.060 & 3.10 & 0.039 \\
2440 & 4.97 & 0.000 & 3.03 & 0.000 \\
\hline
\end{tabular}

the energies with radioactive decay. If thelost gravitational energy is completely converted to heat, the average temperature rise is about $1600^{\circ}, 130^{\circ}$, and $310^{\circ}$ for Venus, 
Table 11. Constants used in the calculation and computed gravitational, and radioactive energies of Venus, Mars, and Mercury.

\begin{tabular}{l|l|l|l}
\hline & Venus & Mars & Mercury \\
\hline Radius* $(\mathrm{km})$ & 6056 & 3380 & 2440 \\
Mass* $\left(10^{27} \mathrm{~g}\right)$ & 4.8655 & 0.6396 & 0.3296 \\
Mass of core $\left(10^{27} \mathrm{~g}\right)$ & 1.404 & 0.08055 & 0.2350 \\
$\begin{array}{c}\text { Loss of gravitational } \\
\text { energy (10 }\end{array}$ & 1.02 & 0.0110 & 0.0134 \\
$\begin{array}{c}\text { Radioactive engs) } \\
\left(10^{88} \text { ergs) }\right.\end{array}$ & 0.902 & 0.119 & 0.0611 \\
\hline
\end{tabular}

* ReYNolds and Summers (1969).

** It is assumed that the radioactivity of these planets equals that of chondritic meteorites.

Mars, and Mercury respectively. In the Earth and Venus the gravitational energy is larger than the energy of radioactive decay. For Mars and Mercury the lost gravitational enegy is much lower than that given by LUBIMOVA (1967) by a simplified calculation. The difference will be attributed to different sizes of core used.

The effect of thermal convection is not taken into account in the present calculation. As being pointed out by LUBIMOva (1969), there is not yet a satisfactory theory of the thermal history of the Earth based on convective transfer of heat. Moreover, as ELSASSER (1963) and BRANCAZIO (1964) pointed out, it seems probable that the viscosity of the mantle materials increases by a factor of $10^{2}$ to $10^{3}$ from the top of the mantle to the bottom. On this basis, the convective flow will be concentrated near the top of the mantle. Such a convective heat transfer will not dominate the thermal history of the whole Earth.

The effect of fusion (absorption of latent heat) is not taken into account in the present calculation. IRIYAMA (1966) has calculated the effect of fusion in a discussion of the thermal history of the Earth, and confirmed that the effect of latent heat is rather minor for the subsequent history.

The initial temperatures within the terrestrial planets fix the date for the differentiation of the mantle (IRIYAMA 1968). However, a lack of data on the thermal state at $4500 \mathrm{My}$ ago precludes detailed conclusions.

\section{Acknowledgements}

I wish to express my hearty thanks to Professor Yasuo SHIMAZU (Nagoya University) for his guidance and supports through the study.

I would like to thank Professor Kumiji IIDA (Nagoya University) for his encouragements. Further, I wish to express my thanks to $\mathrm{Mr}$. Keiichi SHIRAKI and other colleagues, Department of Earth Sciences, Faculty of Science, Nagoya University, for their valuable discussions.

Computations were carried out by a HITAC$5020 \mathrm{E}$ at the computation center, University of Tokyo.

This paper was presented mainly to the annual meeting of the Seismological Society of Japan, November 1968 and partly to the Symposium on the Moon and Planets at the Institute for Space and Aeronautical Science, University of Tokyo, November, 1969.

\section{References}

Anderson, D. L. and R.A. Phinney, Early thermal history of the terrestrial planets, in Mantles of the Earth and Terrestrial Planets, pp. 113-126, Interscience, London, 1967.

Birch. F., Energetics of core formation, J. Geophys. Res., 70, 6217-6221, 1965.

Brancazio, P. J., Covection in the earth's mantle, in The Origin and Evolution of Atmospheres and Oceans, pp. 64-73, John-Wiley \& Sons, New York, 1964.

Bullard, E.C., The interior of the earth, in The Earth as a Planet, pp. 57-137, University of Chicago Press, 1964.

Bullen, K.E., An Introduction to the Theory of Seismology, Cambridge University Press, 1963.

Eddington, A.S., The Internal Constitution of the Stars, Dover Pub., New York, 1959.

Elsasser, W. M., Early history of the earth, in Earth Science and Meteoritics, pp. 1-30, NorthHolland Pub., Amsterdam, 1963.

Fujii, N. and S. Uyeda, Conditions for a once-molton earth to cool, J. Phys. Earth., 14, 15-26, 1966.

Iriyama, J., On the thermal history of the earth, J. Seismol. Soc. Japan, 19, 11-22, 1966.

Iriyama, J., Thermal structure of the terrestrial planets, J. Seismol. Soc. Japan, 21, 14-20, 1968.

Iriyama, J. and Y. Shimazu, A note on the thermal history of the moon, Icarus, 6, 453-457, 1967. 
Lee, W.H.K., Effects of selective fusion on the thermal history of the Earth's mantle, Earth Planet. Sci. Letters, 4, 270-276, 1968.

Lubimova, E. A., Thermal history of the earth with consideration of the variable thermal conductivity of the mantle, Geophys. J., 1, 115-135, 1958.

Lubimova, E. A., Theory of thermal state of the earth's mantle, in The Earth's Mantle, pp. 231323, Academic Press, London, 1967.

Lubimova, E. A., Thermal history of the earth, in The Earth's Crust and Upper Mantle, Geophys. Monograph 13, pp. 63-77. American Geophysical Union, 1969.

MacDonald, G. J.F., Calculations on the thermal history of the earth, J. Geophys. Res., 64, 19672000, 1959.

MacDonald, G.J.F., On the internal constitution of the inner planets, J. Geophys. Res., 67, 29452974, 1962.

Reynolds, R. T. and A. L. Summers, Calculations on the composition of the terrestrial planets, $J$. Geophys. Res., 74, 2494-2511, 1969.

Runcorn, S.K., Convection currents in the earth's mantle, Nature, 195, 1248-1249, '1962.

Runcorn, S. K., Changes in the convective pattern in the earth's mantle and continental drift; evi- dence for a cold origin of the earth, in $A$ Symposium on Continential Drift, pp. 228-251, The Royal Society, London, 1965.

Shimazu, Y., Thermodynamical aspects of terrestrial evolution, J. Earth Sci. Nagoya Univ., 11, 2848, 1963.

Shimazu, Y., Some aspects of formation process of planets in relation to their internal constitution, J. Earth Sci. Nagoya Univ., 13, 59-87, 1965.

Shimazu, Y., Thermodynamical aspects of formation processes of the terrestrial planets and meteorites, Icarus, 6, 143-174, 1967.

Stacey, F. D., A new mechanism for convection in the mantle and continental accretion, Nature, 197, 582-583, 1963.

Tozer, D. C., Thermal history of the earth, Geophys. J., 9, 95-112, 1965.

Urey, H. C., The Planets, Yale University Press, 1952.

Uyeda, S., Thermal history of the earth and the formation of its core, Kagaku, 37, 561-567, Iwanami Pub., Tokyo, 1967a.

Uyeda, S., Terrestrial heat flow, Bull. Volcano. Soc. Japan, 12, 41-59, 1967b.

(Received Aug. 27, 1970) 